\title{
Clinical effectiveness and safety of powered exoskeleton-assisted walking in patients with spinal cord injury: systematic review with meta- analysis
}

\author{
This article was published in the following Dove Press journal: \\ Medical Devices: Evidence and Research \\ 22 March 2016 \\ Number of times this article has been viewed
}

Larry E Miller'

Angela K Zimmermann'

William G Herbert ${ }^{1,2}$

'Miller Scientific Consulting, Inc., Asheville, NC, ${ }^{2}$ Department of Human Nutrition, Foods, and Exercise, Virginia Tech, Blacksburg, VA, USA
Correspondence: Larry E Miller Miller Scientific Consulting, Inc., 1854 Hendersonville Road, \#23I, Asheville, NC, USA

Tel +l 828450 I895

Email larry@millerscientific.com
Background: Powered exoskeletons are designed to safely facilitate ambulation in patients with spinal cord injury (SCI). We conducted the first meta-analysis of the available published research on the clinical effectiveness and safety of powered exoskeletons in SCI patients.

Methods: MEDLINE and EMBASE databases were searched for studies of powered exoskeleton-assisted walking in patients with SCI. Main outcomes were analyzed using fixed and random effects meta-analysis models.

Results: A total of 14 studies (eight ReWalk ${ }^{\mathrm{TM}}$, three $\mathrm{Ekso}^{\mathrm{TM}}$, two Indego ${ }^{\circledR}$, and one unspecified exoskeleton) representing 111 patients were included in the analysis. Training programs were typically conducted three times per week, 60-120 minutes per session, for 1-24 weeks. Ten studies utilized flat indoor surfaces for training and four studies incorporated complex training, including walking outdoors, navigating obstacles, climbing and descending stairs, and performing activities of daily living. Following the exoskeleton training program, $76 \%$ of patients were able to ambulate with no physical assistance. The weighted mean distance for the 6-minute walk test was $98 \mathrm{~m}$. The physiologic demand of powered exoskeleton-assisted walking was 3.3 metabolic equivalents and rating of perceived exertion was 10 on the Borg 6-20 scale, comparable to self-reported exertion of an able-bodied person walking at 3 miles per hour. Improvements in spasticity and bowel movement regularity were reported in $38 \%$ and $61 \%$ of patients, respectively. No serious adverse events occurred. The incidence of fall at any time during training was $4.4 \%$, all occurring while tethered using a first-generation exoskeleton and none resulting in injury. The incidence of bone fracture during training was $3.4 \%$. These risks have since been mitigated with newer generation exoskeletons and refinements to patient eligibility criteria.

Conclusion: Powered exoskeletons allow patients with SCI to safely ambulate in real-world settings at a physical activity intensity conducive to prolonged use and known to yield health benefits.

Keywords: ambulation, Ekso, Indego, orthosis, ReWalk, SCI

\section{Introduction}

Spinal cord injury (SCI) is a traumatic event with a global incidence of 23 cases per million, representing 180,000 cases per annum worldwide. ${ }^{1}$ Despite concerted efforts to develop medical and surgical interventions intended to minimize chronic neurological deficit with acute SCI, recovery of physical function following SCI remains limited due to rapid degenerative processes such as neurotoxicity, vascular dysfunction, glial 
scarring, neuroinflammation, apoptosis, and demyelination. ${ }^{2}$ Consequently, spinal cord-injured patients have increased risks of osteoporosis, cardiovascular disease, respiratory problems, pressure ulcers, and muscular spasticity and contractures compared to the general population. ${ }^{3,4}$

Recovery of locomotion is a main priority for spinal cord-injured patients. ${ }^{5}$ In addition to overcoming the obvious mobility and social issues related to the inability to stand or walk, regular ambulation may profoundly combat secondary medical problems associated with lack of weight-bearing activity in SCI patients. ${ }^{6}$ Orthotic technologies such as hipknee-ankle-foot orthosis (HKAFO) and reciprocating gait orthosis (RGO) have been employed with mixed success as a means of addressing this critical unmet health care need in the SCI population. The main limitation of these devices is a high metabolic demand such that most patients eventually discontinue their use. ${ }^{7-10}$ Since the health benefits of physical activity are largely dependent on exercise frequency and duration, ${ }^{11}$ these traditional orthotic technologies likely have limited utility in ameliorating the chronic effects of inactivity due to SCI.

Powered exoskeletons are prescription devices comprising an external, powered, motorized orthosis that is placed over a person's paralyzed or weakened limbs for the purpose of facilitating standing, walking, climbing stairs, and performing activities of daily living. Powered exoskeletons are classified as class II medical devices by the US Food and Drug Administration. ${ }^{12}$ Although several systematic reviews of powered exoskeletons have recently been published, ${ }^{13-15}$ there are no known meta-analyses that have examined the clinical effectiveness and safety of powered exoskeletons in spinal cord-injured patients. We report herein the first meta-analysis of powered exoskeletons in SCI patients and conclude that exoskeleton use allows safe ambulation in real-world settings at a physical activity intensity conducive to prolonged use and known to yield health benefits.

\section{Methods}

\section{Eligibility criteria and information sources}

This study was performed according to the Preferred Reporting Items for Systematic Reviews and Meta-analyses (PRISMA). ${ }^{16}$ We searched MEDLINE and EMBASE for randomized or nonrandomized controlled studies and prospective or retrospective case series with no date restrictions on the safety and effectiveness of powered exoskeletonassisted walking in adult patients with SCI. The details of the MEDLINE search strategy are listed in Table 1. Additionally, manual searches were conducted using the Directory of Open
Access Journals, Google Scholar, and the reference lists of included papers and other relevant meta-analyses. The final search was conducted on November 30, 2015.

\section{Study selection}

One reviewer selected studies for inclusion in the review. Identified articles were independently assessed by a second reviewer to confirm eligibility. Disagreements were resolved by discussion and consensus. Titles and abstracts were initially screened to exclude all manuscripts published in non-English journals. Next, review articles, commentaries, letters, animal or in vitro studies, studies with less than three patients to eliminate bias inherent with case reports, and obviously irrelevant articles were excluded. Full texts of the remaining manuscripts were retrieved and reviewed. Studies were excluded if mixed diagnoses were included and SCI-specific data were not reported; training was limited to a treadmill; or the protocol utilized upper body exoskeletons, single- or dual-joint exoskeletons, hybrid exoskeletons that required volitional contraction of the lower extremities, or exoskeletons that required use of a walker.

\section{Data extraction}

A database was developed, pilot-tested, and subsequently refined to develop the final data extraction database. One

Table I MEDLINE search strategy

Diagnostic search terms
I. Paralysis
2. Paraplegi*
3. Spinal cord injury
4. SCl
5. Tetraplegi*
Therapeutic search terms
6. Argo
7. Bionic
8. Ekso
9. eLegs
10. Exoskeleton
II. H2
12. Indego
13. Mina
14. Mindwalker
15. Powered
16. ReWalk
17. REX
18. Robot*
19. WPAL
Combination terms
20. or/I-5
21. or/6-19
22. and/20-21

Note: *Represents a wildcard symbol used in a search query to represent end truncation. 
reviewer extracted the data from included studies and a second reviewer checked the extracted data for accuracy. Disagreements were resolved by discussion and consensus.

\section{Outcomes}

Main outcomes were categorized by ambulatory performance, physiological demand, health benefits, and safety. Ambulatory performance outcomes included assessment of ability to ambulate without physical assistance by the end of the training program and distance walked during a 6-minute walk test. Ability to walk without physical assistance was defined as ambulation using crutches or walker, but with no physical contact by a therapist for weight shift or balance support. The 6-minute walk test measures the distance walked over a 6-minute period and serves as an indicator of submaximal aerobic capacity. ${ }^{17}$ Indicators of physiological demand of exoskeleton walking included metabolic equivalents (METs), rating of perceived exertion (RPE), and physiological cost index. The MET concept is useful for expressing the energy cost of physical activities. One MET represents the amount of oxygen consumed during seated rest. In paraplegics, 1 MET is equivalent to $2.7 \mathrm{~mL}$ $\mathrm{O}_{2} / \mathrm{kg} .{ }^{18}$ Each unit increase in METs represents a multiple of the energy used by the body at rest. For reference, exertion with physical activity can be classified as light ( $<3$ METs), moderate (3-6 METs), or vigorous ( $>6$ METs). Rating of perceived exertion values was self-reported according to the Borg 6-20 scale. ${ }^{19}$ For reference, a value of 6 represents no exertion, 9- 11 represents very light to light exertion, 13-15 represents somewhat hard to hard exertion, 17 represents very hard, and 20 represents maximal exertion. Physiological cost index serves as an indicator of ambulation efficiency and was calculated as heart rate during exoskeleton-assisted ambulation minus resting heart rate divided by walking velocity. ${ }^{20}$ Health benefit outcomes included self-reported decreases in spasticity and improvements in bowel movement regularity with exoskeleton use. Safety parameters included serious adverse events, falls, and bone fractures reported at any time during the study, regardless of cause.

\section{Data analysis}

For each main outcome, fixed and random effects metaanalysis models were developed; data from the random effects model were preferentially reported in the manuscript based on the a priori assumption that treatment effects would be heterogeneous, given the differences in exoskeletons and patient characteristics among studies. For each main outcome, the pooled estimate and 95\% confidence interval (CI) were calculated. A forest plot was used to illustrate the individual study findings and the pooled meta-analysis results. We used the $I^{2}$ statistic to estimate heterogeneity of effects across studies with values of $\leq 25 \%, 50 \%$, and $\geq 75 \%$ representing low, moderate, and high inconsistency, respectively. ${ }^{21}$ Statistical analyses were performed using MedCalc version 12.5 (MedCalc Software, Ostend, Belgium) and Comprehensive Meta-Analysis version 2.2 (Biostat, Englewood, NJ, USA).

\section{Results \\ Study selection}

Our initial database search retrieved 105 titles and abstracts; handsearching relevant bibliographies identified three additional records. After screening records for inclusion criteria, 48 full-text articles were reviewed for eligibility. Ultimately, 14 studies ${ }^{22-35}$ representing 111 distinct patients were included in the final analysis. A flow diagram of study identification and selection is shown in Figure 1.

\section{Study characteristics}

All studies included in this review were prospective and conducted at single centers in the US (eleven), the UK (one), Iran (one), and Israel (one). Sample sizes ranged from 3 to 16 patients (median 7).

\section{Patient characteristics}

Mean patient age was 37 years, with males accounting for $83 \%$ of the patients. The level of injury varied considerably among studies, with most injuries located between T1 and T12. Nearly three in four patients presented with complete SCI (Table 2).

\section{Powered exoskeleton training protocols} The ReWalk ${ }^{\mathrm{TM}}$ (ReWalk Robotics, Inc., Marlborough, MA, US) powered exoskeleton was evaluated in eight studies, ${ }^{23-25,27,32-35}$ Ekso $^{\circledR}$ (Ekso Bionics, Richmond, CA, US) in three studies, ${ }^{29-31}$ Indego $^{\mathrm{TM}}$ (Parker Hannifin Corp., Cleveland, OH, US) in two studies, ${ }^{26,28}$ and an unspecified exoskeleton in one study. ${ }^{22}$ Representative images and complete specifications of the ReWalk, Ekso, and Indego powered exoskeletons are available elsewhere. ${ }^{36-38}$ The study of Arazpour et $\mathrm{al}^{22}$ was a randomized cross-over trial comparing exoskeleton, RGO, and HKAFO; the remaining studies were prospective case series. There was considerable variation in training programs among studies, for a duration ranging from 1 to 24 weeks. Typically, programs were conducted three times per week for 60-120 minutes per session. Ten studies $^{22,23,25-27,29,31,33-35}$ utilized training programs exclusively 


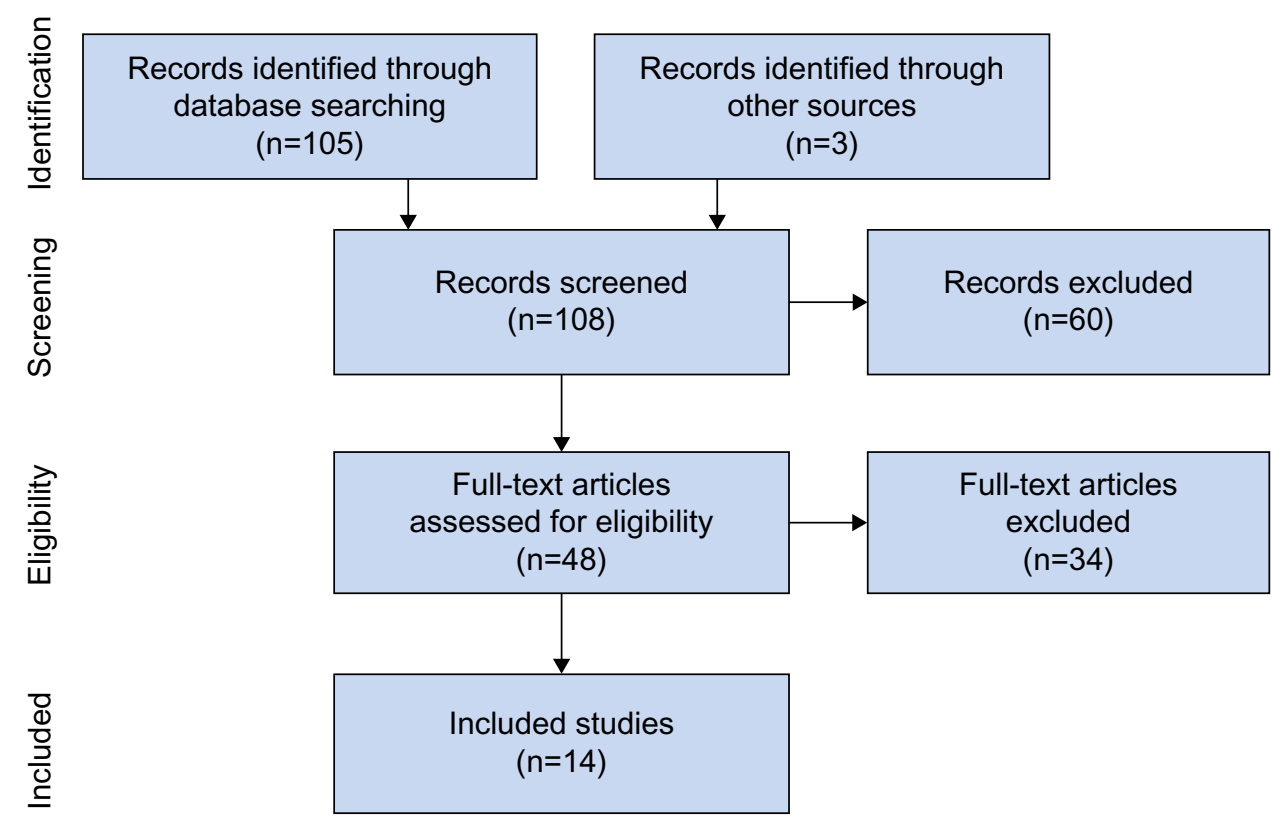

Figure I PRISMA flow diagram.

Abbreviation: PRISMA, Preferred Reporting Items for Systematic Reviews and Meta-Analyses.

on flat indoor surfaces, while four studies ${ }^{24,28,30,32}$ incorporated more complex forms of training, including walking outdoors, navigating obstacles, climbing stairs, and performing activities of daily living (Table 3 ).

\section{Ambulatory performance}

Following the exoskeleton training program, 76\% (95\% CI: $59 \%-90 \%$ ) of patients were able to ambulate with no physical assistance (Figure 2). Significant heterogeneity among studies was noted for this outcome $\left(I^{2}=73 \%, P<0.001\right)$. In the randomized controlled trial of Arazpour et al, ${ }^{22} 6$-minute walk test velocity and distance were superior with powered exoskeleton vs RGO and HKAFO (Figure 3). Across all powered exoskeleton studies, the weighted mean distance covered during a 6-minute walk test was $98 \mathrm{~m}$ (95\% CI: 80-117 m) (Figure 4). Significant heterogeneity among studies was also noted for this outcome $\left(I^{2}=85 \%, P<0.001\right)$.

\section{Physiological demand}

In the randomized controlled trial of Arazpour et al, ${ }^{22}$ the physiological cost index was $\sim 50 \%$ lower with powered exoskeleton vs RGO and HKAFO (Figure 3). Across all powered

Table 2 Baseline patient characteristics

\begin{tabular}{|c|c|c|c|c|c|c|c|c|c|c|c|}
\hline \multirow[t]{2}{*}{ Study } & \multirow[t]{2}{*}{$\mathbf{N}$} & \multirow{2}{*}{$\begin{array}{l}\text { Male } \\
\text { (n) }\end{array}$} & \multirow{2}{*}{$\begin{array}{l}\text { Age } \\
\text { (years) }\end{array}$} & \multirow{2}{*}{$\begin{array}{l}\text { Height } \\
(\mathrm{cm})\end{array}$} & \multirow{2}{*}{$\begin{array}{l}\text { Weight } \\
\text { (kg) }\end{array}$} & \multirow{2}{*}{$\begin{array}{l}\text { BMI } \\
\left(\mathrm{kg} / \mathrm{m}^{2}\right)\end{array}$} & \multirow[t]{2}{*}{ LOI* } & \multicolumn{3}{|c|}{ AIS } & \multirow{2}{*}{$\begin{array}{l}\text { Time post-injury } \\
\text { (years) }\end{array}$} \\
\hline & & & & & & & & $\overline{\mathbf{A}}$ & B & $\bar{C}$ & \\
\hline Arazpour et $\mathrm{al}^{21}$ & 5 & 3 & 27 & 167 & 58 & 21 & T6-TI2 & I & 4 & 0 & 2.0 \\
\hline Asselin et $\mathrm{al}^{22}$ & 8 & 7 & 46 & - & 78 & - & TI-TII & 7 & I & 0 & 5.9 \\
\hline Benson et $\mathrm{al}^{23}$ & 10 & 10 & 32 & - & - & - & C7-LI & 7 & 0 & 3 & 4.8 \\
\hline Esquenazi et $\mathrm{al}^{24}$ & 12 & 8 & 38 & 177 & 74 & 23 & T3-TI2 & - & - & - & 7.4 \\
\hline Evans et $\mathrm{al}^{25}$ & 5 & 4 & 42 & 180 & 70 & 21 & T6-TI2 & 5 & 0 & 0 & I I.0 \\
\hline Fineberg et $\mathrm{al}^{26}$ & 6 & 5 & 45 & 174 & 7I & 23 & TI-TII & 5 & I & 0 & 6.3 \\
\hline Hartigan et $\mathrm{al}^{27}$ & 16 & 13 & 36 & 177 & 75 & 24 & C5-LI & - & - & - & - \\
\hline Kolakowsky-Hayner et $\mathrm{al}^{28}$ & 7 & 5 & 30 & - & - & - & T4-TII & 7 & 0 & 0 & 0.9 \\
\hline Kozlowski et al ${ }^{29}$ & 7 & 7 & 36 & 178 & 82 & 24 & C4-LI & 3 & 1 & 3 & 0.5 \\
\hline Kressler et $\mathrm{al}^{30}$ & 3 & 2 & 30 & 177 & 75 & 24 & TI-T9 & 3 & 0 & 0 & - \\
\hline Spungen et $\mathrm{al}^{31}$ & 7 & 6 & 44 & 175 & 73 & 24 & TI-TII & 5 & 2 & 0 & 5.6 \\
\hline Talaty et $\mathrm{al}^{32}$ & 12 & - & - & - & - & - & C7-TI2 & - & - & - & - \\
\hline Yang et $\mathrm{al}^{33}$ & 12 & 10 & 46 & 173 & 75 & 25 & C8-TII & 9 & 2 & I & 6.8 \\
\hline Zeilig et $\mathrm{al}^{34}$ & 6 & 6 & 33 & - & - & - & T5-TI2 & - & - & - & 5.0 \\
\hline
\end{tabular}

Notes: *Represents the cephalad to caudal range. Dash indicates unspecified.

Abbreviations: AIS, American Spinal Injury Association Impairment Scale; BMI, body mass index; LOI, level of injury. 
Table 3 Powered exoskeleton training protocols

\begin{tabular}{|c|c|c|c|c|c|c|c|c|c|c|c|}
\hline \multirow[t]{2}{*}{ Study } & \multirow{2}{*}{$\begin{array}{l}\text { Study } \\
\text { design }\end{array}$} & \multirow[t]{2}{*}{ Exoskeleton } & \multicolumn{5}{|c|}{ Training environment } & \multicolumn{4}{|c|}{ Training volume } \\
\hline & & & $\begin{array}{l}\text { Indoor } \\
\text { walking }\end{array}$ & $\begin{array}{l}\text { Outdoor } \\
\text { walking }\end{array}$ & Obstacles & Stairs & $\overline{A D L s}$ & $\begin{array}{l}\text { No of } \\
\text { sessions }\end{array}$ & $\begin{array}{l}\text { Session } \\
\text { length } \\
\text { (min) }\end{array}$ & $\begin{array}{l}\text { Sessions } \\
\text { per } \\
\text { week }\end{array}$ & $\begin{array}{l}\text { Program } \\
\text { duration } \\
\text { (weeks) }\end{array}$ \\
\hline Arazpour et $\mathrm{al}^{21}$ & RCT & - & $x$ & & & & & 24 & 120 & 3 & 8 \\
\hline Asselin et $\mathrm{al}^{22}$ & PCS & ReWalk & $x$ & & & & & 37 & [75] & 3 & 12 \\
\hline Benson et $\mathrm{a}^{23}$ & PCS & ReWalk & $x$ & $x$ & $x$ & $x^{a}$ & $x^{b}$ & 20 & 120 & 2 & 10 \\
\hline Esquenazi et al ${ }^{24}$ & PCS & ReWalk & $x$ & & & & & 24 & [83] & 3 & 8 \\
\hline Evans et $\mathrm{a}^{25}$ & PCS & Indego & $x$ & & & & & 6 & - & - & - \\
\hline Fineberg et $\mathrm{al}^{26}$ & PCS & ReWalk & $x$ & & & & & {$[72]$} & {$[90]$} & 3 & 24 \\
\hline Hartigan et $\mathrm{al}^{27}$ & PCS & Indego & $x$ & $x^{c}$ & $X^{d}$ & & $x^{e}$ & 5 & 90 & 5 & I \\
\hline Kolakowsky- & PCS & Ekso & $X^{f}$ & & & & & 6 & 58 & 1 & 6 \\
\hline \multicolumn{12}{|l|}{ Hayner et $\mathrm{al}^{28}$} \\
\hline Kozlowski et $\mathrm{al}^{29}$ & PCS & Ekso & $x$ & & $X^{g}$ & & $X^{h}$ & 19 & 120 & {$[1.5]$} & {$[13]$} \\
\hline Kressler et $\mathrm{al}^{30}$ & PCS & Ekso & $X^{f}$ & & & & & 18 & 60 & 3 & 6 \\
\hline Spungen et $\mathrm{al}^{31}$ & PCS & ReWalk & $x$ & $X^{i}$ & $X^{i}$ & $X^{b}$ & $X^{k}$ & 45 & {$[90]$} & 3 & {$[15]$} \\
\hline Talaty et $\mathrm{a}^{32}$ & PCS & ReWalk & $x$ & & & & & 24 & [75] & 3 & 8 \\
\hline Yang et $\mathrm{al}^{33}$ & PCS & ReWalk & $x$ & & & & & 55 & 90 & - & - \\
\hline Zeilig et al ${ }^{34}$ & PCS & ReWalk & $x$ & & & & & 14 & 50 & - & - \\
\hline
\end{tabular}

Notes: Brackets represent an estimate. Dash indicates unspecified, blank spaces indicate not utilized. alncludes walking up and down stairs; bincludes visiting a café, upright

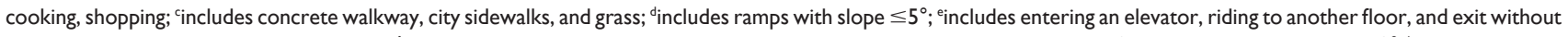
requiring the elevator door to be held open; includes tethered indoor walking; ;includes walking on carpet, rough concrete surfaces, and ramps with slope $\leq 8^{\circ}$; ' includes opening doors, pushing button to summon, enter, and exit elevators, and standing at counter and retrieve an item from high cupboard; 'includes walking on concrete and uneven ground surfaces; includes walking on carpet, up and down a slight slope, and up and down a curb; kincludes navigating a push button electric door, an elevator, and a revolving door. Abbreviations: ADLs, activities of daily living; PCS, prospective case series; RCT, randomized controlled trial; min, minutes.

exoskeleton studies, the metabolic demand of exoskeletonassisted walking was 3.3 METs (95\% CI: 2.2-4.4 METs) (Figure 5). For reference, 3.3 METs is equivalent to the self-reported exertion of an able-bodied individual walking at 3 miles per hour. Significant heterogeneity was identified among studies $\left(I^{2}=98 \%, P<0.001\right)$. Rating of perceived exertion during powered exoskeleton walking was $10(95 \%$ CI: 9-11) and results were consistent among studies $\left(I^{2}=0 \%\right.$,

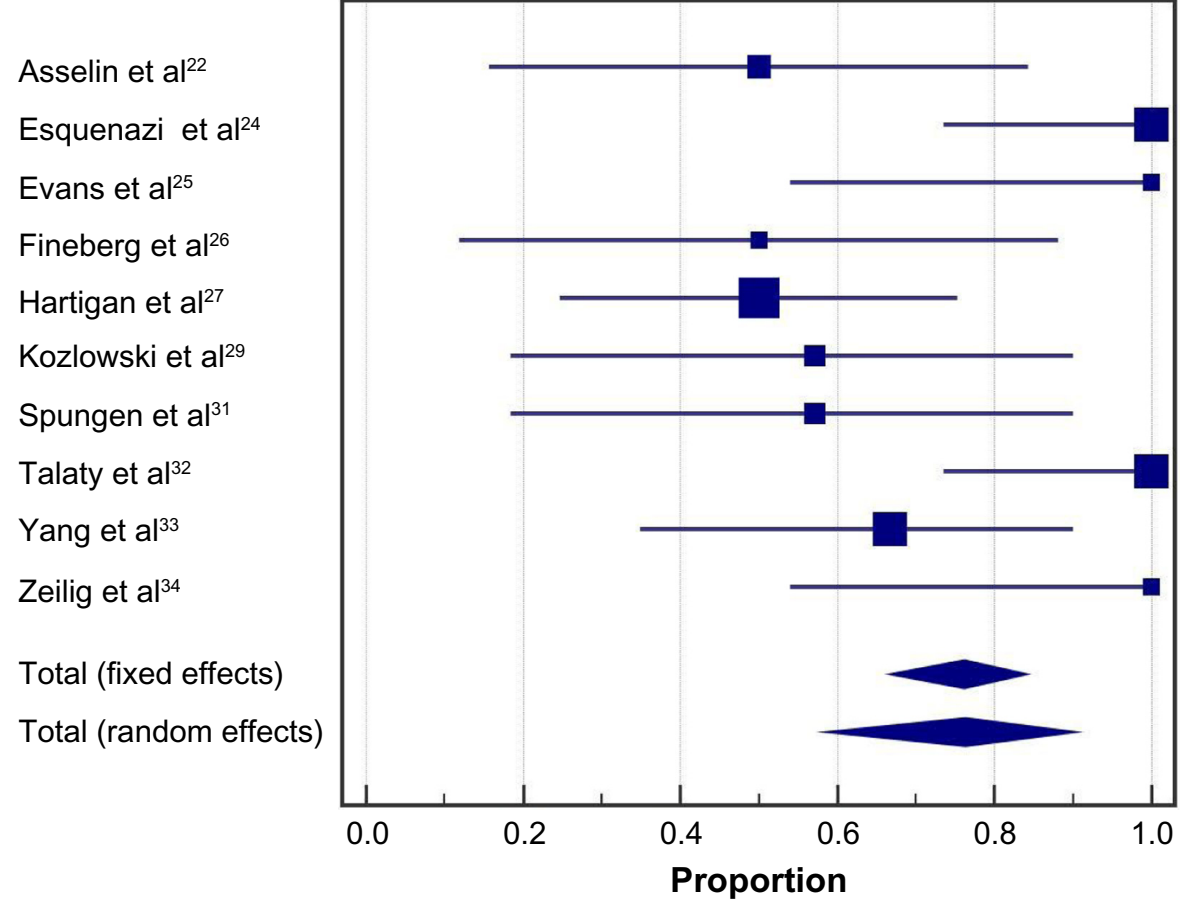

Figure 2 Ability to ambulate using a powered exoskeleton without physical assistance.

Notes: Data represent the proportion of subjects who were able to ambulate using an exoskeleton without physical assistance at the end of the training period. Fixed effects estimates: $76.2 \%$ (95\% Cl: 66.7\%-84.1\%); random effects estimates: $76.2 \%$ (95\% Cl: 58.6\%-90.1\%); $P^{2}=73 \%, P<0.001$.

Abbreviation: $\mathrm{Cl}$, confidence interval. 
A

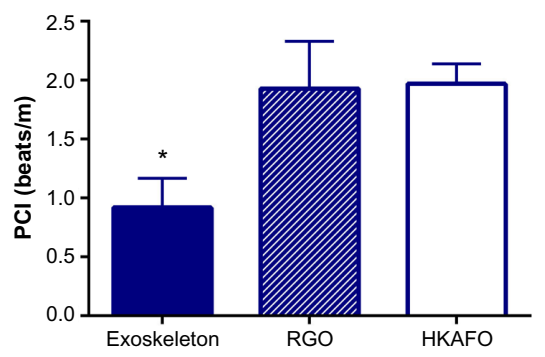

B

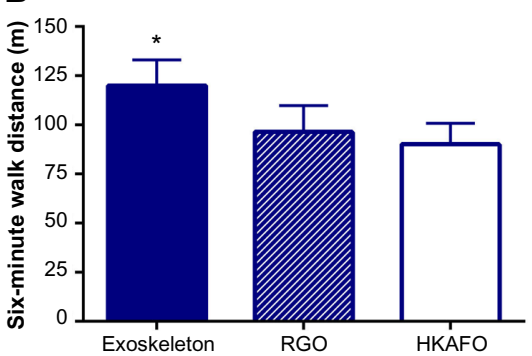

C

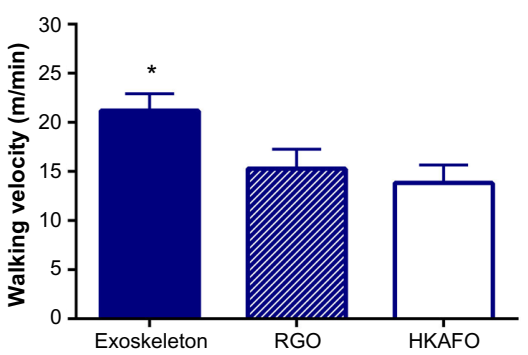

Figure 3 Outcomes of randomized controlled trial comparing powered exoskeleton, reciprocating gait orthosis, and hip-knee-ankle-foot orthosis.

Notes: A is PCI, B is 6-min walk distance, and $\mathbf{C}$ is walking velocity. *Exoskeleton outcomes superior to RGO and HKAFO for walking velocity (both $P<0.00 \mathrm{I}$ ), 6-minute walk distance ( $P=0.03$ vs RGO; $P<0.01$ vs HKAFO), and $P C l$ (both $P<0.00$ I).

Abbreviations: HKAFO, hip-knee-ankle-foot orthosis; PCI, physiological cost index; RGO, reciprocating gait orthosis.

$P=0.97$ ) (Figure 6). An RPE of 10 represents very light to light exertion. ${ }^{19}$

\section{Health benefits}

Health benefits related to exoskeleton-assisted ambulation were inconsistently reported. In five studies, 38\% $(95 \%$ CI: $19 \%-59 \%$ ) of patients reported decreases in spasticity with exoskeleton training; heterogeneity among studies was moderate $\left(I^{2}=46 \%, P=0.12\right)$ (Figure 7$)$. In three studies, $61 \%$ (95\% CI: 20\%-95\%) of patients reported improvements in bowel movement regularity with exoskeleton training
(Figure 8). Significant heterogeneity was identified among studies $\left(I^{2}=81 \%, P<0.01\right)$.

\section{Safety}

No serious adverse events were reported in any included study. The incidence of a fall at any time during the training program was 4.4\% (95\% CI: 1.0\%-10.0\%) (Figure 9). All three reported falls occurred in a single study ${ }^{29}$ while tethered and none resulted in injury. Falls were due to programming errors using a first-generation Ekso exoskeleton in two participants and due to malfunctioning of specialized forearm

Arazpour et $\mathrm{al}^{21}$
Asselin et $\mathrm{al}^{22}$
Benson et $\mathrm{al}^{23}$
Esquenazi et $\mathrm{al}^{24}$
Evans et al ${ }^{25}$
Hartigan et $\mathrm{al}^{27}$
Spungen et al ${ }^{31}$
Yang et al
Zeilig et al

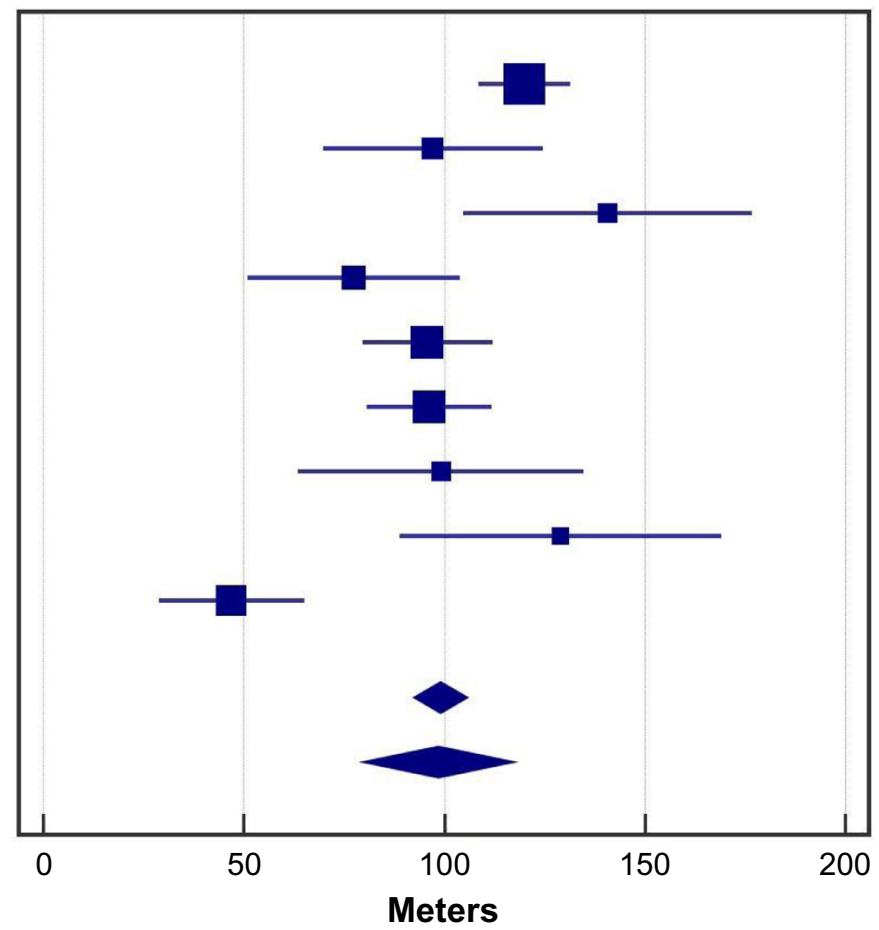

Figure 4 Six-minute walk test results with a powered exoskeleton.

Notes: Data represent the number of meters walked with exoskeleton at the end of the training period. Fixed effects estimates: $99 \mathrm{~m}$ ( $95 \% \mathrm{Cl}$ : $92-106 \mathrm{~m})$; random effects estimates: $98 \mathrm{~m}$ (95\% Cl: $80-\mathrm{II} 7 \mathrm{~m}) ; l^{2}=85 \%, P<0.00$ I.

Abbreviation: $\mathrm{Cl}$, confidence interval. 


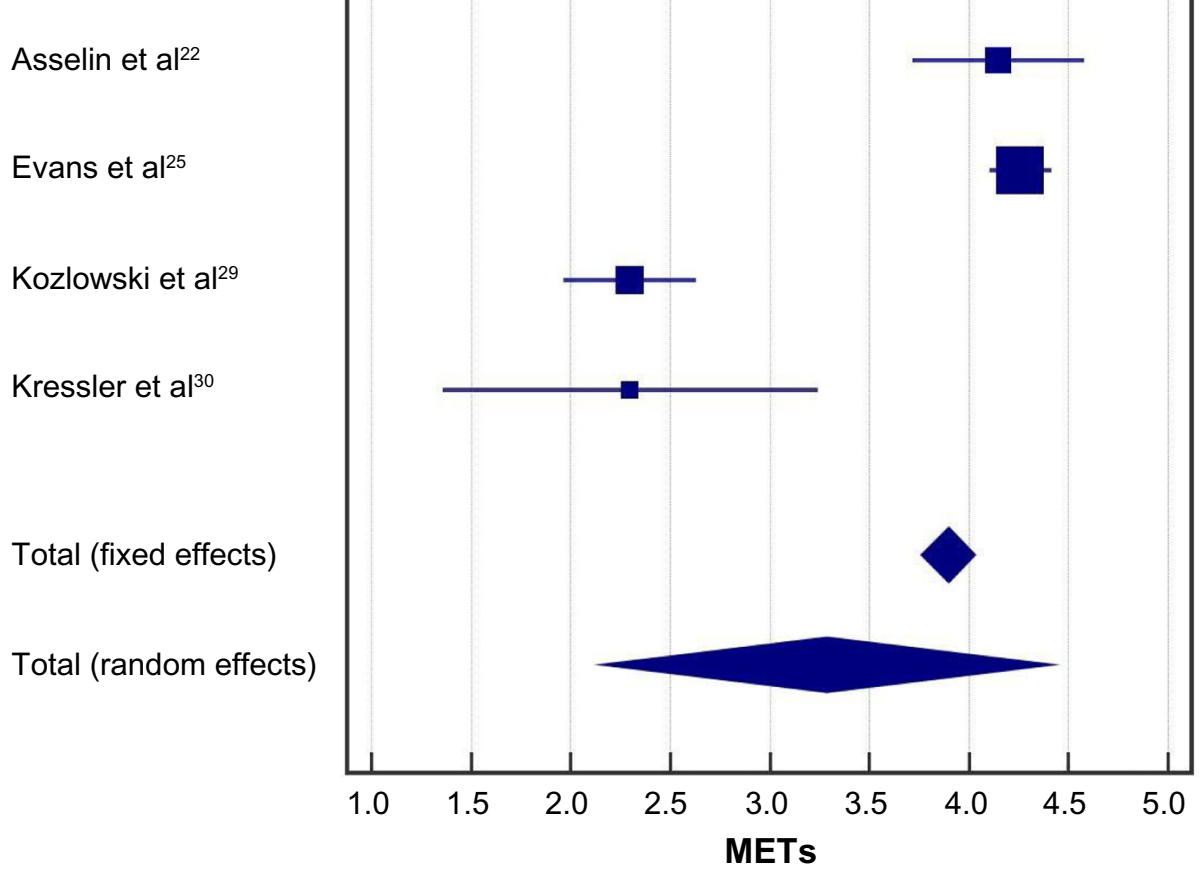

Figure 5 Metabolic equivalents with powered exoskeleton walking.

Notes: Data represent the number of metabolic equivalents (METs) required for exoskeleton walking at the end of the training period. METs were calculated as I MET per $2.7 \mathrm{~mL} \mathrm{O} / \mathrm{kg}$ based on the estimated or measured maximal aerobic capacity values, unless otherwise specified. Fixed effects estimates: $3.9 \mathrm{METs}$ (95\% Cl: 3.8, $4.0 \mathrm{METs}$ ); random effects estimates: $3.3 \mathrm{METs}(95 \% \mathrm{Cl}: 2.2,4.4 \mathrm{METs}) ; P^{2}=98 \%, P<0.00 \mathrm{I}$.

Abbreviation: $\mathrm{Cl}$, confidence interval.

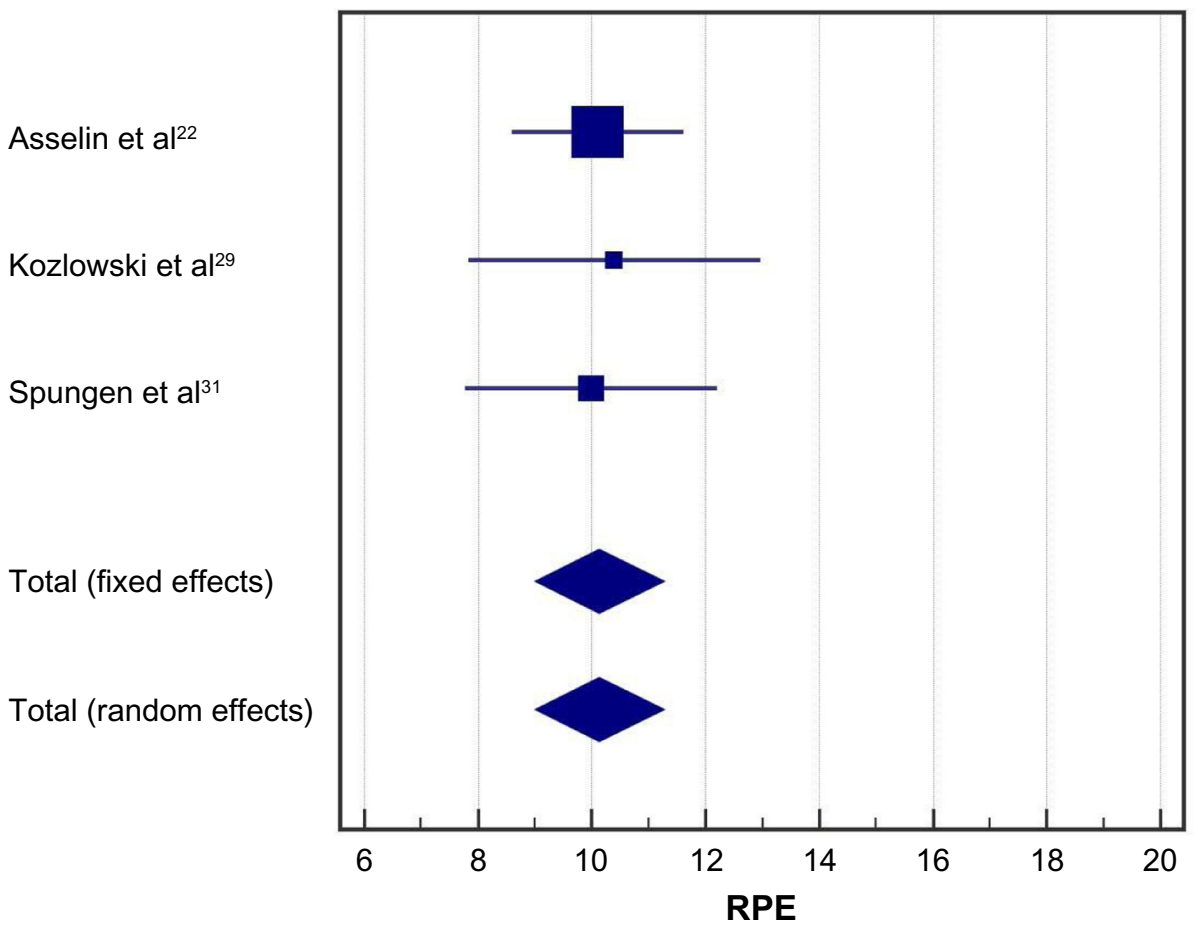

Figure 6 Rating of perceived exertion with powered exoskeleton walking.

Notes: Data represent subjective rating of perceived exertion (RPE; Borg 6-20 scale) required for exoskeleton walking at the end of the training period. Fixed and random effects estimates: I0.I (95\% Cl: 9.0, II.3); $P^{2}=0 \%, P=0.97$.

Abbreviations: $\mathrm{Cl}$, confidence interval; RPE, rating of perceived exertion. 
Esquenazi et $\mathrm{al}^{24}$

Kolakowsky-Hayner et $\mathrm{al}^{28}$

Kozlowski et al ${ }^{29}$

Kressler et $\mathrm{al}^{30}$

Zeilig et $\mathrm{al}^{34}$

Total (fixed effects)

Total (random effects)

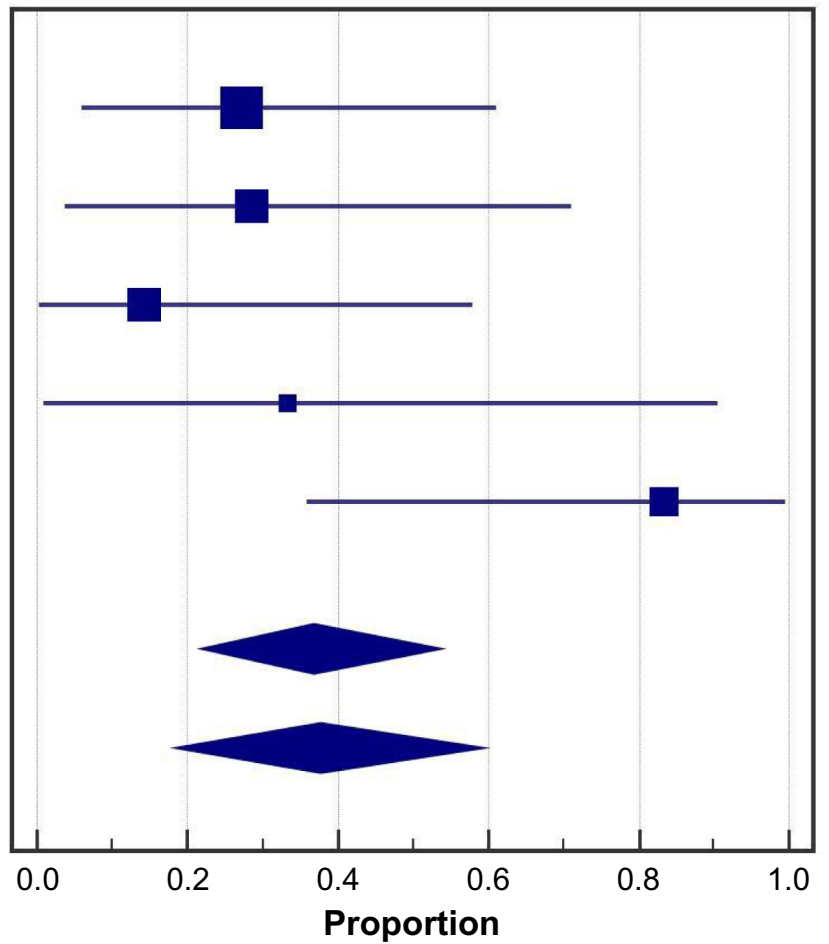

Figure 7 Spasticity decreases with powered exoskeleton training.

Notes: Data represent the proportion of subjects who reported decreases in spasticity with exoskeleton training. Fixed effects estimates: $36.7 \%$ ( $95 \%$ Cl: $21.9 \%$, $53.6 \%)$; random effects estimates: $37.7 \%(95 \% \mathrm{Cl}: 18.5 \%, 59.2 \%) ; P^{2}=46 \%, P=0.12$.

Abbreviation: $\mathrm{Cl}$, confidence interval.

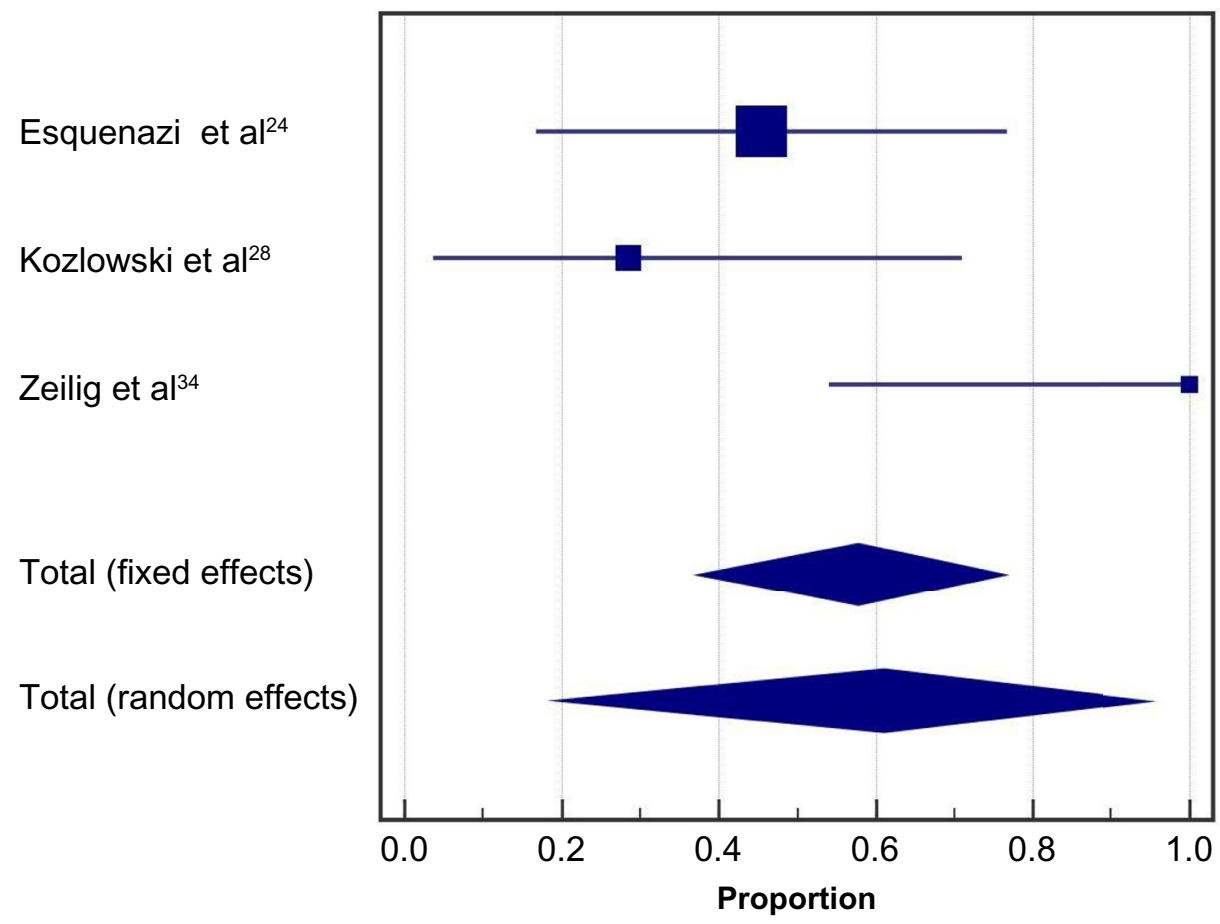

Figure 8 Improvements in bowel movement regularity with powered exoskeleton training.

Notes: Data represent the proportion of subjects who reported improvements in bowel movement regularity with exoskeleton training. Fixed effects estimates: $57.7 \%$ ( $95 \%$ $\mathrm{Cl}: 37.3 \%, 76.3 \%)$; random effects estimates: $60.9 \%$ (95\% Cl: $19.5 \%, 94.5 \%) ; P^{2}=81 \%, P<0.01$.

Abbreviation: $\mathrm{Cl}$, confidence interval. 


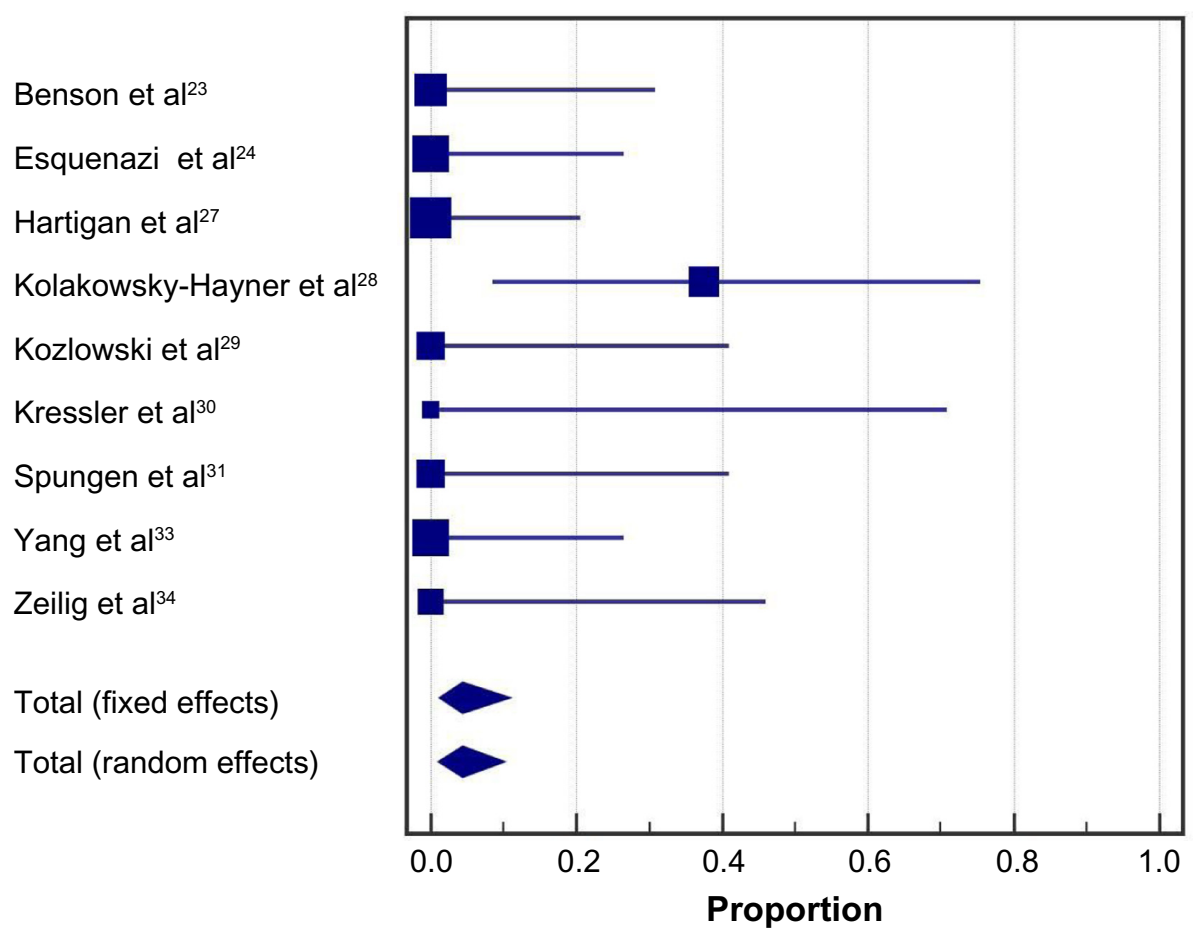

Figure 9 Incidence of falls with a powered exoskeleton.

Notes: Data represent the proportion of subjects who experienced a fall at any point during the training period. Fixed effects estimates: $4.3 \%$ ( $95 \%$ Cl: I.I\%, I $0.8 \%)$; random effects estimates: $4.4 \%(95 \% \mathrm{Cl}: 1.0 \%, 10.0 \%) ; P=11 \%, P=0.34$.

Abbreviation: $\mathrm{Cl}$, confidence interval.

crutches that had been discontinued in one participant. The incidence of bone fracture at any time during the training program was 3.4\% (95\% CI: $0.7 \%-8.1 \%$ ) (Figure 10 ). The single reported event was a hairline talus fracture that required no treatment in a patient who did not undergo bone density screening. ${ }^{24}$

\section{Discussion}

This is the first known meta-analysis of the clinical effectiveness and safety of powered exoskeletons in SCI patients. The results of this study show that use of a powered exoskeleton allows safe ambulation in real-world settings at a physical activity intensity conducive to prolonged use and known to yield health benefits.

Most patients included in this review presented with complete SCI. Generally, less than $5 \%$ of such patients have the ability to ambulate without physical assistance. Following an exoskeleton training program, $67 \%$ of patients in this review were able to engage in exoskeleton-assisted ambulation without physical assistance. Since training programs were limited to only five or six sessions in some studies, ${ }^{26,28,29}$ it is plausible that the ability to ambulate without physical assistance may be somewhat higher with training programs of adequate duration that emphasize identification of safe environments for exoskeleton use, use of safety features, and operation in environments representative of actual use.

For studies that reported 6-minute walk test results after exoskeleton training, the gait speed achieved suggested encouraging potential for independent ambulation in home and community environments. Physiologic demands during powered exoskeleton ambulation averaged 3.3 METs for the included studies, which represents $24 \%-35 \%$ of peak oxygen uptake during exercise in SCI patients. ${ }^{23}$ These data suggest that exoskeleton use allows SCI patients to engage in physical activity at an intensity that conveys health benefits, yet does not result in early fatigue, as with older orthotic technologies such as HKAFO and RGO. Powered exoskeleton walking perceived exertion corresponded to fairly light to light exertion, implying that patients felt they could sustain ambulation for extended durations. This assertion is supported by the fact that several studies in this review utilized exoskeletonassisted training programs up to 2 hours duration per session. In contrast, spinal cord-injured adults can ambulate only $20-50 \mathrm{~m}$ at a time with an RGO before stopping due to fatigue. ${ }^{10}$ The randomized controlled trial of Arazpour et $\mathrm{al}^{22}$ 


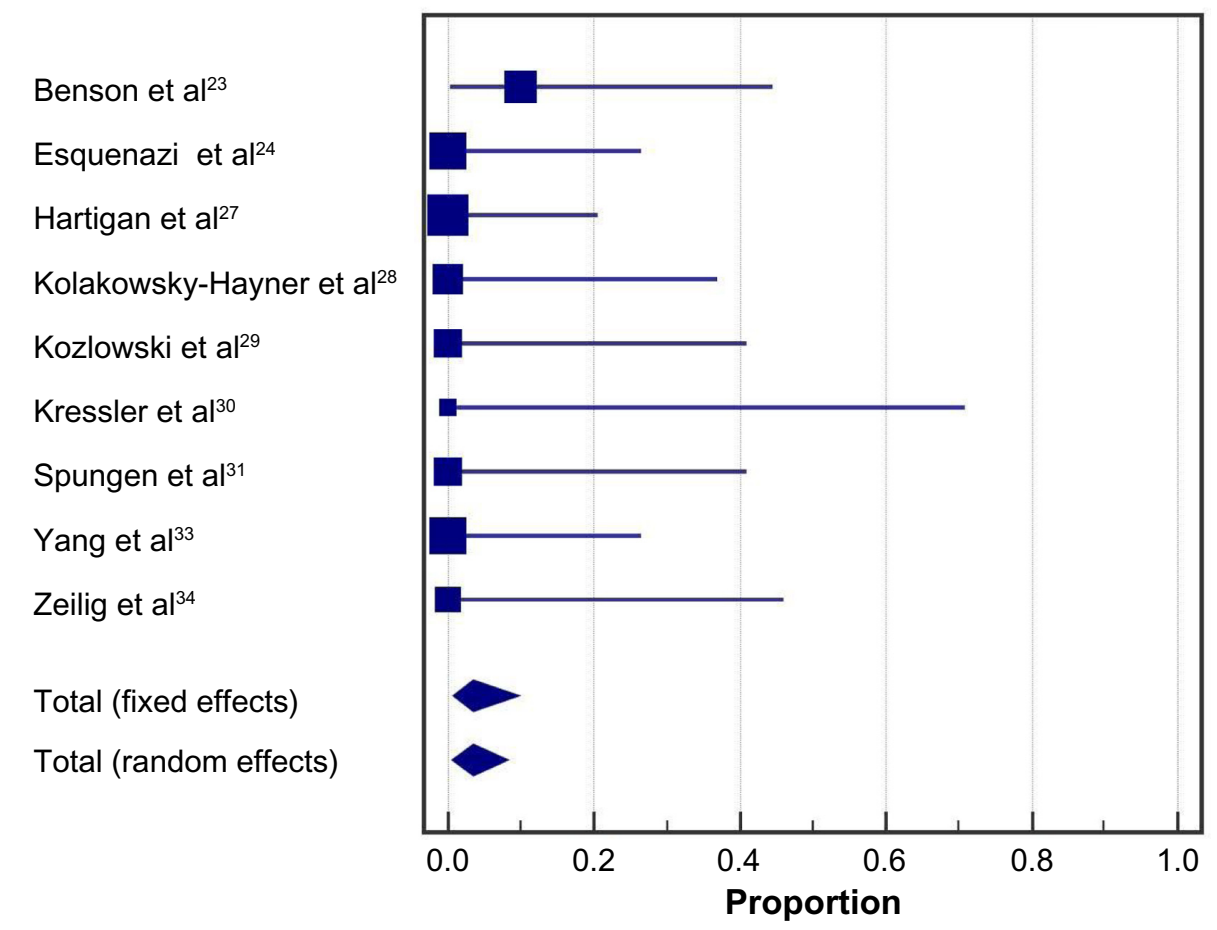

Figure 10 Incidence of fractures with a powered exoskeleton.

Notes: Data represent the proportion of subjects who experienced a bone fracture at any point during the training period. Fixed effects estimates: $3.4 \%$ ( $95 \% \mathrm{Cl}: 0.7 \%, 9.5 \%)$; random effects estimates: $3.4 \%(95 \% \mathrm{Cl}: 0.7 \%, 8.1 \%) ; P=0 \%, P=0.98$.

Abbreviation: $\mathrm{Cl}$, confidence interval.

confirmed that SCI patients can walk faster and with less effort using a powered exoskeleton vs RGO and HKAFO. Physical activity at 3.3 METs maintained for only 1 hour per day, 3 days per week, corresponding to 10 MET hours per week, is associated with preventive health benefits including cardiovascular and all-cause mortality risk reduction of $20 \%$ in the general adult population. ${ }^{6}$ For SCI patients, those same health benefits should be a reasonable expectation. In addition, several other benefits may accrue to SCI patients as a result of intermittent standing and habitual ambulating activity with the powered exoskeleton, including increasing upper body muscular fitness, ${ }^{39}$ minimizing declines in bone mineral density by periodic exposure to gravitational and muscular loading forces ${ }^{40}$ improved circulatory response, ${ }^{41}$ and countering the independent health risks associated with prolonged sitting. ${ }^{42}$ Indeed, clinically relevant improvements were found in self-reports for muscle spasticity and bowel movement regularity following exoskeleton training. A potential focus for future research would be to assess the long-term health and cost benefits associated with chronic powered exoskeleton use. Assuming regular exoskeleton use sufficient to yield the aforementioned health benefits, it is likely that the initial expense of providing personal exoskeletons for home use to individuals with SCI (typically
$\$ 70,000-\$ 100,000)$ may be offset by savings attributable to prevention of physical maladies and associated costs in SCI patients, which may ultimately result in overall savings to the health care system.

The safety of exoskeleton-assisted ambulation was demonstrated by no reports of serious adverse events and a low incidence of tethered falls and fractures that were subsequently addressed by refinements to exoskeleton design and patient selection criteria. Falls were identified in a single study ${ }^{29}$ that used an early prototype exoskeleton; injuries to subjects were prevented by a tethering device. The instance of a hairline talus fracture occurring in a subject who did not undergo bone density screening ${ }^{24}$ suggests that osteoporosis/ osteopenia should be viewed as a relative contraindication for SCI patients being considered for exoskeleton ambulatory training. Although there are subtle differences when comparing features of available exoskeleton, generally accepted criteria for safe use include ability to stand using an assistive device and absence of severe neurological injury, severe spasticity, significant contractures, osteoporosis, and existing fractures. On balance, falls and fractures are known risks for all assisted walking devices for SCI patients such as KAFO and RGO, which mandate similar patient screening measures. 
Four of the 14 studies included more complex forms of ambulatory training relevant to daily living..$^{24,28,30,32}$ Examples of these activities included walking on uneven or carpeted surfaces and grades, negotiating curbs outdoors, climbing stairs, entering/exiting of elevators, and ordering at a café. It is important to note that in the studies that utilized complex training, no serious adverse events, falls, or fractures were reported. While these activities were performed under the supervision of trained clinicians, the outcomes indicate that a powered exoskeleton uniquely facilitates independent performance of tasks relevant to the home and community settings.

\section{Limitations}

As with any meta-analysis, interpretation of outcomes may be confounded by issues related to individual study designs and by issues inherent in the analysis of summary data. There was considerable variation in the consistency of outcome reporting among studies. Development of minimum reporting standards for powered exoskeleton clinical trials is recommended to facilitate comparisons among studies. Additionally, the number of studies limited our ability to explore sources of heterogeneity such as age, level of injury, and duration of injury. Despite these limitations, this report represents the most comprehensive synthesis of data for powered exoskeleton-assisted walking in patients with SCI.

\section{Conclusion}

In conclusion, powered exoskeletons allow patients with SCI to safely ambulate in real-world settings at a physical activity intensity conducive to prolonged use and known to yield health benefits.

\section{Disclosure}

This research was supported by ReWalk Robotics, Inc. (Marlborough, MA, USA). The authors report no conflicts of interest in this work.

\section{References}

1. Lee BB, Cripps RA, Fitzharris M, Wing PC. The global map for traumatic spinal cord injury epidemiology: update 2011, global incidence rate. Spinal Cord. 2014;52(2):110-116.

2. Sandrow-Feinberg HR, Houle JD. Exercise after spinal cord injury as an agent for neuroprotection, regeneration and rehabilitation. Brain Res. 2015;1619:12-21

3. Jensen MP, Truitt AR, Schomer KG, Yorks ton KM, Baylor C, Molton IR. Frequency and age effects of secondary health conditions in individuals with spinal cord injury: a scoping review. Spinal Cord. 2013;51(12):882-892.

4. Sezer N, Akkus S, Ugurlu FG. Chronic complications of spinal cord injury. World J Orthop. 2015;6(1):24-33.

5. Ditunno PL, Patrick M, Stineman M, Ditunno JF. Who wants to walk? Preferences for recovery after SCI: a longitudinal and cross-sectional study. Spinal Cord. 2008;46(7):500-506.
6. Arem H, Moore SC, Patel A, et al. Leisure time physical activity and mortality: a detailed pooled analysis of the dose-response relationship. JAMA Intern Med. 2015;175(6):959-967.

7. Bernardi M, Canale I, Castellano V, Di Filippo L, Felici F, Marchetti M. The efficiency of walking of paraplegic patients using a reciprocating gait orthosis. Paraplegia. 1995;33(7):409-415.

8. Scivoletto G, Petrelli A, Lucente LD, et al. One year follow up of spinal cord injury patients using a reciprocating gait orthosis: preliminary report. Spinal Cord. 2000;38(9):555-558.

9. Franceschini M, Baratta S, Zampolini M, Loria D, Lotta S. Reciprocating gait orthoses: a multicenter study of their use by spinal cord injured patients. Arch Phys Med Rehabil. 1997;78(6):582-586.

10. Sykes L, Edwards J, Powell ES, Ross ER. The reciprocating gait orthosis: long-term usage patterns. Arch Phys Med Rehabil. 1995; 76(8):779-783.

11. Foulds HJ, Bredin SS, Charlesworth SA, Ivey AC, Warburton DE. Exercise volume and intensity: a dose-response relationship with health benefits. Eur J Appl Physiol. 2014;114(8):1563-1571.

12. Electronic Code of Federal Regulations. Part 890-Physical Medicine Devices. $\$ 890.3480$ Powered lower extremity exoskeleton. HYPERLINK "http://www.ecfr.gov/cgi-bin/text-idx?SID=9b627fd1822b $8 \mathrm{fcd} 87 \mathrm{ad} 660 \mathrm{db} 602 \mathrm{de} 1 \mathrm{c} \& \mathrm{mc}=$ true $\&$ node $=\mathrm{pt} 21.8 .890 \& \mathrm{rgn}=\operatorname{div} 5$ " $\backslash 1$ "se21.8.890_13480" http://www.ecfr.gov/cgi-bin/text-idx?SID=9b $627 \mathrm{fd} 1822 \mathrm{~b} 8 \mathrm{fcd} 87 \mathrm{ad} 660 \mathrm{db} 602 \mathrm{de} 1 \mathrm{c} \& \mathrm{mc}=$ true $\&$ node $=\mathrm{pt} 21.8 .890 \& \mathrm{rg}$ n=div5\#se21.8.890_13480. Accessed December 18, 2015.

13. Federici S, Meloni F, Bracalenti M, De Filippis ML. The effectiveness of powered, active lower limb exoskeletons in neurorehabilitation: a systematic review. NeuroRehabilitation. 2015;37(3):321-340.

14. Lajeunesse V, Vincent C, Routhier F, Careau E, Michaud F. Exoskeletons' design and usefulness evidence according to a systematic review of lower limb exoskeletons used for functional mobility by people with spinal cord injury. Disabil Rehabil Assist Technol. Epub 2015 Sep 4.

15. Louie DR, Eng JJ, Lam T; Spinal Cord Injury Research Evidence Research Team. Gait speed using powered robotic exoskeletons after spinal cord injury: a systematic review and correlational study. $\mathrm{J} \mathrm{Neu}$ roeng Rehabil. 2015;12:82.

16. Liberati A, Altman DG, Tetzlaff J, et al. The PRISMA statement for reporting systematic reviews and meta-analyses of studies that evaluate health care interventions: explanation and elaboration. Ann Intern Med. 2009;151(4):W65-W94.

17. Butland RJ, Pang J, Gross ER, Woodcock AA, Geddes DM. Two-, six-, and 12-minute walking tests in respiratory disease. Br Med J (Clin Res Ed). 1982;284(6329):1607-1608.

18. Collins EG, Gater D, Kiratli J, Butler J, Hanson K, Langbein WE. Energy cost of physical activities in persons with spinal cord injury. $\mathrm{Med} \mathrm{Sci}$ Sports Exerc. 2010;42(4):691-700.

19. Borg GA. Psychophysical bases of perceived exertion. Med Sci Sports Exerc. 1982;14(5):377-381

20. Kawashima N, Taguchi D, Nakazawa K, Akai M. Effect of lesion level on the orthotic gait performance in individuals with complete paraplegia. Spinal Cord. 2006;44(8):487-494.

21. Higgins JP, Thompson SG, Deeks JJ, Altman DG. Measuring inconsistency in meta-analyses. BMJ. 2003;327(7414):557-560.

22. Arazpour M, Bani MA, Hutchins SW, Jones RK. The physiological cost index of walking with mechanical and powered gait orthosis in patients with spinal cord injury. Spinal Cord. 2013;51(5):356-359.

23. Asselin P, Knezevic S, Kornfeld S, et al. Heart rate and oxygen demand of powered exoskeleton-assisted walking in persons with paraplegia J Rehabil Res Dev. 2015;52(2):147-158.

24. Benson I, Hart K, Tussler D, van Middendorp JJ. Lower-limb exoskeletons for individuals with chronic spinal cord injury: findings from a feasibility study. Clin Rehabil. 2016;30(1):73-84.

25. Esquenazi A, Talaty M, Packel A, Saulino M. The ReWalk powered exoskeleton to restore ambulatory function to individuals with thoraciclevel motor-complete spinal cord injury. Am J Phys Med Rehabil. 2012;91(11):911-921. 
26. Evans N, Hartigan C, Kandilakis C, Pharo E, Clesson I. Acute cardiorespiratory and metabolic responses during exoskeleton-assisted walking overground among persons with chronic spinal cord injury. Top Spinal Cord Inj Rehabil. 2015;21(2):122-132.

27. Fineberg DB, Asselin P, Harel NY, et al. Vertical ground reaction forcebased analysis of powered exoskeleton-assisted walking in persons with motor-complete paraplegia. J Spinal Cord Med. 2013;36(4): 313-321.

28. Hartigan C, Kandilakis C, Dalley S, et al. Mobility outcomes following five training sessions with a powered exoskeleton. Top Spinal Cord Inj Rehabil. 2015;21(2):93-99.

29. Kolakowsky-Hayner SA, Crew J, Moran S, Shah A. Safety and feasibility of using the Ekso bionic exosksleton to aid ambulation after spinal cord injury. J Spine. 2013;S4:003.

30. Kozlowski AJ, Bryce TN, Dijkers MP. Time and effort required by persons with spinal cord injury to learn to use a powered exoskeleton for assisted walking. Top Spinal Cord Inj Rehabil. 2015;21(2):110-121.

31. Kressler J, Thomas CK, Field-Fote EC, et al. Understanding therapeutic benefits of overground bionic ambulation: exploratory case series in persons with chronic, complete spinal cord injury. Arch Phys Med Rehabil. 2014;95(10):1878.e4-1887.e4.

32. Spungen AM, Asselin PK, Fineberg DB, Kornfeld SD, Harel NY. Exoskeletal-assisted walking for persons with motor-complete paraplegia. Paper presented at: NATO Science and Technology Organization; Milan, Italy; April 15-17, 2013.

33. Talaty M, Esquenazi A, Briceno JE. Differentiating ability in users of the ReWalk(TM) powered exoskeleton: an analysis of walking kinematics. IEEE Int Conf Rehabil Robot. 2013;2013:6650469.
34. Yang A, Asselin P, Knezevic S, Kornfeld S, Spungen AM. Assessment of in-hospital walking velocity and level of assistance in a powered exoskeleton in persons with spinal cord injury. Top Spinal Cord Inj Rehabil. 2015;21(2):100-109.

35. Zeilig G, Weingarden H, Zwecker M, Dudkiewicz I, Bloch A, Esquenazi A. Safety and tolerance of the ReWalk exoskeleton suit for ambulation by people with complete spinal cord injury: a pilot study. J Spinal Cord Med. 2012;35(2):96-101.

36. ReWalk Robotics. Available from: http://rewalk.com/. Accessed January 31, 2016.

37. Ekso Bionics. Available from: http://www.eksobionics.com/. Accessed January 31, 2016.

38. Corp. PH. Available from: http://www.indego.com/indego/en/home. Accessed January 31, 2016.

39. Hicks AL, Martin Ginis KA, Pelletier CA, Ditor DS, Foulon B, Wolfe DL. The effects of exercise training on physical capacity, strength, body composition and functional performance among adults with spinal cord injury: a systematic review. Spinal Cord. 2011;49(11):1103-1127.

40. Astorino TA, Harness ET, Witzke KA. Effect of chronic activity-based therapy on bone mineral density and bone turnover in persons with spinal cord injury. Eur J Appl Physiol. 2013;113(12):3027-3037.

41. Milia R, Roberto S, Marongiu E, et al. Improvement in hemodynamic responses to metaboreflex activation after one year of training in spinal cord injured humans. Biomed Res Int. 2014;2014:893468.

42. Stamatakis E, Rogers K, Ding D, et al. All-cause mortality effects of replacing sedentary time with physical activity and sleeping using an isotemporal substitution model: a prospective study of 201,129 midaged and older adults. Int J Behav Nutr Phys Act. 2015;12:121.
Medical Devices: Evidence and Research

\section{Publish your work in this journal}

Medical Devices: Evidence and Research is an international, peerreviewed, open access journal that focuses on the evidence, technology, research, and expert opinion supporting the use and application of medical devices in the diagnosis, treatment and management of clinical conditions and physiological processes. The identification of novel

\section{Dovepress}

devices and optimal use of existing devices which will lead to improved clinical outcomes and more effective patient management and safety is a key feature. The manuscript management system is completely online and includes a quick and fair peer-review system. Visit http://www. dovepress.com/testimonials.php to read real quotes from authors. 